\title{
Long-term Resting Metabolic Rate Analysis in Pregnancy and Weight Loss Interventions
}

\author{
Shayok Chakraborty ${ }^{1}$, Teresa $\mathrm{Wu}^{2}$, Erica Forzani ${ }^{3}$, Corrie Whisner ${ }^{4}$ and David Jackemeyer ${ }^{5}$ \\ ${ }^{1}$ Department of Computer Science, Florida State University \\ shayok@cs.fsu.edu \\ ${ }^{2}$ School of Computing, Informatics, and Decision Systems Engineering, Arizona State University \\ teresa.wu@asu.edu \\ ${ }^{3}$ School for Engineering of Matter, Transport and Energy, and Center for Bioelectronics and Biosensors, the Biodesign \\ Institute, Arizona State University \\ eforzani@asu.edu \\ ${ }^{4}$ School of Nutrition and Health Promotion, Arizona State University \\ cwhisner@asu.edu \\ ${ }^{5}$ Center for Bioelectronics and Biosensors, the Biodesign Institute, Arizona State University \\ djackeme@asu.edu
}

\begin{abstract}
In this paper, we first studied the change in resting metabolic rate (RMR) of 4 women during their pregnancy period. We retrospectively analyzed published data, which lacked rigorous statistical analysis. We introduced new data that helps to define RMR baseline variabilities and further compare the RMR fluctuations in steady physiological conditions (no pregnancy, no weight/diet/exercise regime change) to assess "true" RMR changes that can guide healthy weight management in pregnancy and other conditions. For each subject, the change in the RMR values were computed as the difference between the values during the metabolic rate inspection period and the baseline values. This difference was compared against the difference values of a reference subject, using a two-sided paired t-test at the significance level of 5\%. Our results indicated that some subjects exhibit a statistically significant increase, some exhibit a decrease while others show no significant statistical variation in RMR values during pregnancy. These are important findings that demystify the old idea that the RMR of a pregnant woman "always" increases since she is generating a new life; rather, individualized physiological processes can produce metabolic changes that cannot be
\end{abstract}

Shayok Chakraborty et al. This is an open-access article distributed under the terms of the Creative Commons Attribution 3.0 United States License, which permits unrestricted use, distribution, and reproduction in any medium, provided the original author and source are credited.

https://doi.org/10.36001/IJPHM.2021.v12i4.3077 generalized and need individual RMR measurements throughout pregnancy. The insights gained from this study were then applied to retrospectively analyze the RMR of 20 subjects during a 6-month pilot weight loss intervention with $89 \%$ efficiency in weight loss. Our analysis revealed that there was no significant decrease in metabolic activities at the end of the program. Although this contradicts the belief that weight loss is associated with a decrease in metabolic activities, our results can be explained by the fact that subjects adhered to a healthy nutritional diet and regular exercise during the pro- gram; thus, the effect of weight loss on decreasing the RMR was counter-balanced by the effect of healthier diet and exercise on increasing the RMR, which helped in maintaining a steady and healthy metabolic rate. Both studies, pregnancy and weight loss interventions indicated that changes in the metabolic rate of pregnant women and individuals undergoing weight loss interventions are unpredictable, therefore there is an urgent need to implement personalized practices of weight management by periodically measuring RMR and adjusting food caloric intakes based on the individual's metabolic rate.

\section{INTRODUCTION}

Resting metabolic rate (RMR), also known as Resting energy expenditure (REE), is the energy required to support basic metabolic functions of a person (during a time period of strict and steady resting conditions) (Criscione \& Durr- 
Gross, 2010; Nestle \& Nesheim, 2012). Indirect calorimetry devices can be used to detect exchange of gases during metabolic activities and compute the energy (kcal/day) needed to sup- port life (Weir, 1949, 1990). The energy requirements for life and growth during pregnancy is much higher than in the non-pregnant state (Jackemeyer, Forzani, \& Whisner, 2017). Thus, proper measurement of REE and characterization of longitudinal metabolic changes during pregnancy is key to determining daily caloric intake needs and preventing adverse maternal and fetal health risks. Further, obesity has become endemic in the U.S., with rates increasing worldwide (Spring et al., 2017): 40\% of adults (Hales, Carroll, Fryar, \& Ogden, 2017; Wolf \& Colditz, 1998; Flegal, Carroll, Ogden, \& John-son, 2002; Bray, 2004; Campos, Saguy, Ernsberger, Oliver, \& Gaesser, 2006; Finkelstein, Trogdon, Cohen, \& Dietz, 2009; Criscione, Durr-Gross, \& Stebler, 2013) and $18 \%$ of children under 18 (Orsi, Hale, \& Lynch, 2011) in the U.S. are obese, affecting every segment of the U.S. population. The root cause of obesity and weight gain is a surplus of individual dietary energy intake relative to energy expenditure (McArdle, Katch, \& Katch, 2010; Manore, Meyer, \& Thompson, 2009). For a person to meet their weight goals, the number of calories consumed must take into account the number of caloriesburned during daily activities. Therefore, measuring an individual's energy expenditure is necessary to develop and implement effective weight management courses and intervention programs (Criscione et al., 2013; McDoniel, Nelson, \& Thomson, 2008; Wahrlich, Anjos, Going, \& Lohman, 2006; Jones, 2006; Heshka, Yang, Wang, Burt, \& Pisunyer, 1990; Elliot, Goldberg, Kuehl, \& Bennett, 1989, 1987). The goal of this research was to analyze long-term resting metabolic rates and develop prediction models for resting metabolic rate changes. We include two user populations in this study: (i) adult women during their pregnancy period; and (ii) individuals who participated in a weight loss pilot intervention for 6 months. Our analysis sheds light on some new insights on the variation of REE during pregnancy and weight loss interventions.

\section{STUdY 1: REE OF WOMEN DURING THEIR Pregnancy Period}

To test the hypothesis whether the REE always increases during pregnancy, in our first study, we analyzed the REE of 4 adult women during their pregnancy period. All the participants were in good health and over the age of 18 years. Subjects were excluded if they had type 1 or 2 diabetes, high blood pressure, or intestinal or metabolic conditions that could affect energy metabolism. Each participant was given a mobile indirect calorimeter for selfassessment of REE. The calorimetry device was the BreezingTM analyzer (www.breezing.com), which uses indirect calorimetry to measure the exchange of oxygen and carbon dioxide from inhaled and exhaled breath (Seagle, Strain, Makris, \& Reeves, 2009). It is the first mobile, wireless, user-friendly device that performs resting metabolic measurement based on indirect calorimetry with capability for remote patient assessment. It measures RMR / REE by measuring the rate of $\mathrm{O} 2$ consumption and $\mathrm{CO} 2$ production in breath. The device had been validated for accuracy with the gold standard Douglas Bag Method, showing excellent agreement between the two methods (Xian et al., 2015). The participants were provided with an REE-adjusted daily calorie intake recommendation and the captured data was uploaded and stored on iPhones. Please refer (Jackemeyer et al., 2017) for further details about the data collection.

The results are shown in Figure 1. We compared the change in the REE ( $\triangle$ REE) values of the 4 subjects against those of the reference subjects (showing normal physiological fluctuations - baseline). For each subject, the change in the REE values were computed as the difference between the values during the $\mathrm{EE}$ inspection period and the intrasubject's base- line values ( $\Delta$ REE). This difference was compared against the difference values of the reference subject, using a two- sided paired t-test at the significance level of $5 \%$. The results indicated that subjects 1 and 3 exhibited a statistically significant increase in the REE values while subject 4 showeda decrease in the REE value during the period. For subject 2, the values did not show any statistically significant variation. This is a significant research finding and is contrary to the popular belief that the REE of a pregnant woman always increases, since she is generating a new life. Our results suggest that physiological processes produce metabolic changesthat are unique to every individual and cannot be generalized.

\section{STUDY 2: REE OF SUBJECTS DURING A PILOT WEIGHT LOSS INTERVENTION}

In our second study, 20 subjects were recruited (14 females and 6 males) to participate in a pilot weight loss intervention. All subjects had T2DM or were at high risk of developing diabetes. Physical, metabolic and blood measurements were performed on Day 1 and at 6 months. Throughout the study, participants electronically recorded weight, caloric in-take, and activities on an iPad loaded with the relevant apps. Each subject was also provided with a metabolic rate analyzerto assess their measured REE weekly during the month intervention period. Subjects adherence to measurements were different and while 1 subject recorded measurements for the first 3 months, others continued even after ending the intervention period, reaching records for a period of 9 months. For each subject, the weight loss was noted, together with the change in measured REE values during the intervention period (please refer (Stump et al., 2017) for further details about the data collection). The variation in the measured REEvalues was compared against the baseline value using a two-sided paired t-test at the significance level of $5 \%$. 
The results are reported in Table 1. For each participant, we included the time period of the intervention, the initial weight, the weight change (final - initial weight), the number of REE measurements within the given time period, its mean and standard deviation and the outcome of our analysis(whether or not there was a significant change in the $\mathrm{REE}$ as compared to the baseline values at $\mathrm{p}<0.05)$. We excluded 3 subjects (15, 16 and 19) from our analysis, as they had very few (less than 5) REE measurements during the entire period of the intervention. Out of the 17 subjects analyzed, 5 depicted a significant decrease, 4 depicted a significant increase and 8 depicted no significant change in the REE.

Figures 2(a) and 2(b) depict the results of subjects 6 and 13 respectively, where both the measured REE and the body weight are plotted against time. We note that there is a reduction in weight from 157 to $153.8 \mathrm{lbs}$ with a minimum of $151.8 \mathrm{lbs}$ for subject 6 , and from 249 to $216.3 \mathrm{lbs}$ for subject 13. Both these subjects lost a significant amount of body weight during the intervention program. However, there was no significant change in the REE as compared to the baseline values (first measured REE on day 1 of the interventions) at $p<0.05$. We excluded 3 subjects $(15,16$ and 19) from our analysis, as they had very few (less than 5) REE measurements during the entire period of the intervention. Out of the 17 sub- jects analyzed, 5 depicted a significant loss of body weight during the intervention program, specially subject 13 experienced a significant weight loss of $13 \%$. However, there was no statistically significant reduction in their REE, which im-plies that they maintained a steady metabolic rate during their weight loss. This contradicts the popular belief that weight loss is always associated with a decrease in metabolic activities. Our inspection revealed that the participants adhered to ahealthy diet and exercised regularly, which negated the effects of weight loss and helped in maintaining a steady metabolic rate. Regarding the other subjects that showed significant increases of REE even when they experienced a weight loss between 2 and $17 \mathrm{lbs}$, the increase may have been due higher metabolic functions in the overall body. The increase of activity (higher blood flow) as well as healthier organs (e.g. liver with $20 \%$, heart and kidney with $20 \%$ of total $\mathrm{REE}$ ) functions may have been the contributors to this change (Kinney \& Tucker, 1992). However, these subjects lost a significant amount of body weight during the intervention program. However, there was no significant change in the REE as compared to the baseline values (first measured REE on day 1 of the interventions) at $p<0.05$. We excluded 3 subjects (15, 16 and 19) from our analysis, as they had very few (less than 5) REE measurements during the entire period of the intervention. Out of the 17 sub- jects analyzed, 5 depicted a significant loss of body weight during the intervention program, especially subject 13 experienced a significant weight loss of $13 \%$.
However, there was no statistically significant reduction in their REE, which im- plies that they maintained a steady metabolic rate during their weight loss. This contradicts the popular belief that weight loss is always associated with a decrease in metabolic activities. Our inspection revealed that the participants adhered to a healthy diet and exercise regularly, which negated the effectsof weight loss and helped in maintaining a steady metabolic rate.
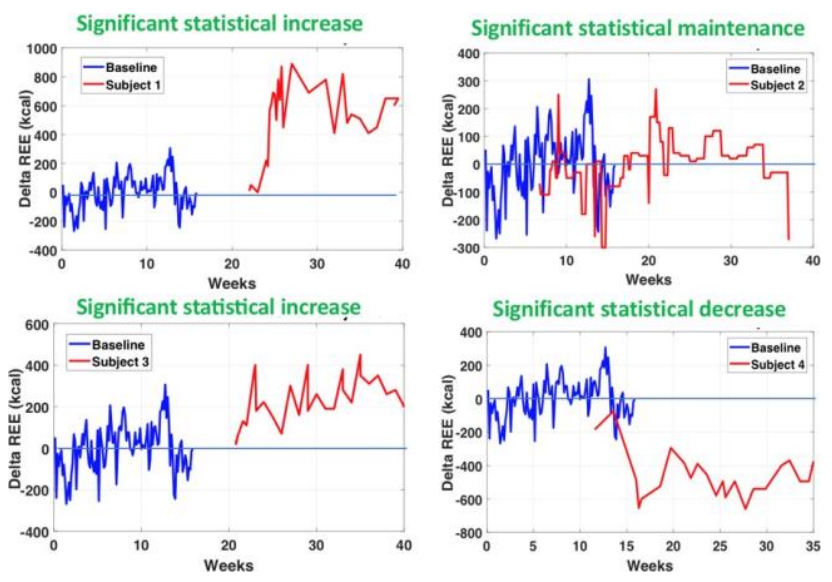

Figure 1. Analysis of REE changes for 4 adult women during their pregnancy period. The results indicated that subjects 1 and 3 exhibited a statistically significant increase in the REE values while subject 4 showed a decrease in the REE value during theobservation period. For subject 2, the values did not show any statistically significant variation

Regarding the other subjects that showed significant increases of REE even when they experienced a weight loss between 2 and $17 \mathrm{lbs}$, the increase may have been due higher metabolic functions in the overall body. The increase of activity (higher blood flow) as well as healthier organs (e.g., liver with $20 \%$, heart and kidney with $20 \%$ of total REE) functions may have been the contributors to this change (Kinney\& Tucker, 1992).

\section{Conclusion AND Discussion}

Both studies, pregnancy and weight loss interventions indicate that changes in the metabolic rate of pregnant women and individuals undergoing weight loss interventions are un-predictable, therefore there is an urgent need to implement personalized practices of weight management by periodically measuring REE and adjusting food caloric intakes based on management as much as a glucose measurement is reinforced in the field of diabetes management. All individuals are unique, and populationbased trends are only representative of the population and not of the individual. In this regard, the use of statistical methods of analysis of REE patterns over time are necessary to bring to the clinical practice. Further, these analysis in connection to prediction models of weight management could be paired with already known appropriate interventions to help combat the obesity epidemic. In this 
study, use of the Breezing system was important, as it allowed re- mote longitudinal REE data assessment.

\begin{tabular}{|c|c|c|c|c|c|c|c|}
\hline $\begin{array}{c}\text { Sub. } \\
\text { No. }\end{array}$ & $\begin{array}{c}\text { Time } \\
\text { (months) }\end{array}$ & Initial Wt. & Wt. Change & $\begin{array}{c}\text { No. REE } \\
\text { Meas. }\end{array}$ & REE Mean & REE Std & Analysis Outcome \\
\hline 1 & 8 & 236.5 & -14.8 & 18 & 2442.2 & 350.28 & Significant increase \\
\hline 2 & 5 & 194.9 & -1 & 31 & 1389.7 & 177.2 & Significant decrease \\
\hline 3 & 7 & 206.9 & 2 & 19 & 1861.1 & 180.39 & No significant change \\
\hline 4 & 6 & 229.9 & -17 & 14 & 2008.6 & 115.54 & Significant increase \\
\hline 5 & 6 & 260.9 & -4.4 & 15 & 1811.3 & 167.15 & No significant change \\
\hline 6 & 4 & 157 & -3.2 & 27 & 1577.8 & 99.31 & No significant change \\
\hline 7 & 2 & 200.7 & -6 & 12 & 1390.8 & 138.65 & No significant change \\
\hline 8 & 6 & 187.9 & -6 & 26 & 1842.6 & 301.41 & Significant decrease \\
\hline 9 & 9 & 252.3 & -10.4 & 14 & 1684.3 & 297.31 & No significant change \\
\hline 10 & 9 & 266.9 & -2 & 29 & 1422.8 & 177.01 & No significant change \\
\hline 11 & 7 & 170 & -4 & 13 & 1059.4 & 138.03 & No significant change \\
\hline 12 & 6 & 205.9 & -27.9 & 28 & 1300.7 & 147.11 & Significant decrease \\
\hline 13 & 7 & 249 & -32.7 & 16 & 2306.9 & 205.09 & No significant change \\
\hline 14 & 6 & 223.9 & -15.9 & 16 & 1295 & 85.47 & Significant decrease \\
\hline 17 & 7 & 199.9 & -2 & 24 & 1852.1 & 232.37 & Significant increase \\
\hline 18 & 6 & 170.2 & -5.4 & 23 & 1302.2 & 121.46 & Significant increase \\
\hline 20 & 3 & 173 & -5 & 9 & 1544.4 & 195.64 & Significant decrease \\
\hline
\end{tabular}

Table 1. Analysis of REE changes for 17 subjects during a pilot weight loss intervention. For each participant, we tabulate the duration of the intervention (in months), the initial weight (in lbs.), the weight change (final - initial weight, in lbs.), the mean and standard deviation of the REE during the intervention and whether or not there was a statistically significant variation in the REE. The significance was computed using a two-sided paired t-test at the significance level of 5\%.

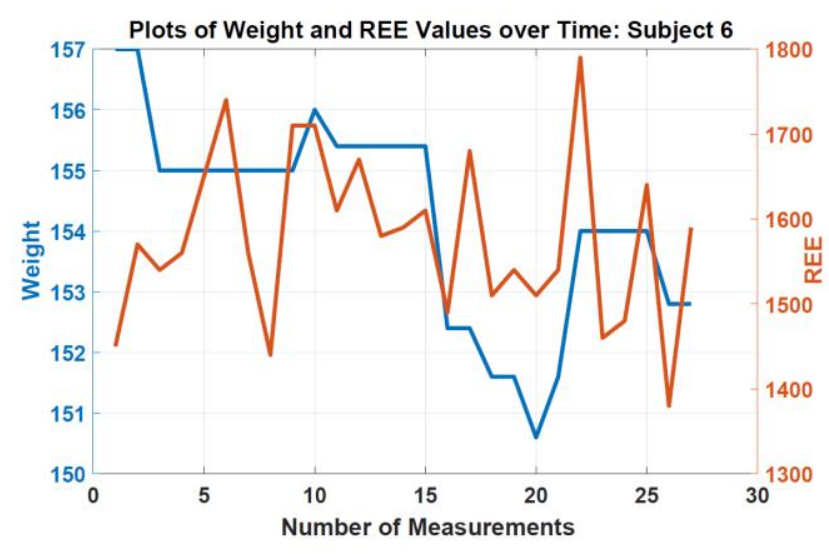

(a) Plot of Weight and REE Values over Time for Subject 6

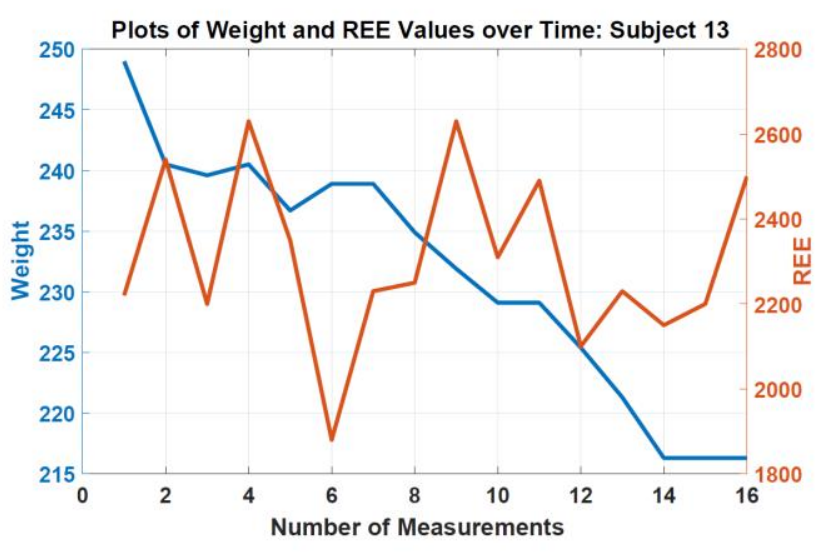

(b) Plot of Weight and REE Values over Time for Subject 13

Figure 2. Plot of the weight and REE for subjects 6 and 13 during the weight loss intervention. Both subjects depicted a reduction in body weight, but there was no statistically significant change in their REE. 


\section{REFERENCES}

Bray, G. (2004). Medical consequences of obesity. Journal Of Clinical Endocrinology and Metabolism, 89(6),25832589.

Campos, P., Saguy, A., Ernsberger, P., Oliver, E., \& Gaesser, G. (2006). The epidemiology of overweight and obesity: public health crisis or moral panic? International Journal Of Epidemiology, 35(1), 55-60.

Criscione, L., \& Durr-Gross, M. (Eds.). (2010). Eating healthy and dying obese. Vitasanas $\mathrm{GmbH}$.

Criscione, L., Durr-Gross, M., \& Stebler, K. (2013). Calogenetic balance, an educational program for lifelong weight control on measured resting metabolic rate and intake of favorite foods, promotes adherence and success rate. In European congress on obesity.

Elliot, D., Goldberg, L., Kuehl, K., \& Bennett, W. (1987). Sustained decrement in resting metabolic-rate following weight loss. Clinical Research, 35(3), A365-A365.

Elliot, D., Goldberg, L., Kuehl, K., \& Bennett, W. (1989). Sustained depression of the resting metabolic-rate after massive weight loss. American Journal Of Clinical Nutrition, 49(1), 93-96.

Finkelstein, E., Trogdon, J., Cohen, J., \& Dietz, W. (2009). Annual medical spending attributable to obesity: Payer- and service-specific estimates. Health Affairs, 28(5), W822-W831.

Flegal, K., Carroll, M., Ogden, C., \& Johnson, C. (2002). Prevalence and trends in obesity among u.s. adults, 1999-2000. Journal of the American Medical Association, 288(14), 1723-1727.

Hales, C., Carroll, M., Fryar, C., \& Ogden, C. (2017). Prevalence of obesity among adults and youth: United states, 2015-2016. In Nchs data brief, no 288.

Heshka, S., Yang, M., Wang, J., Burt, P., \& Pisunyer, F. (1990). Weigth-loss and change in resting metabolicrate. American Journal of Clinical Nutrition, 52(6), 981-986.

Jackemeyer, D., Forzani, E., \& Whisner, C. (2017). Study of resting energy expenditure and weight changes during pregnancy. Global Journal of Obesity, Diabetes and Metabolic Syndrome, 4(1), 16-23.

Jones, V. (2006). Resting metabolic rate: A critical, primary care screening test. Med Gen Med, 8(2).

Kinney, J., \& Tucker, H. (Eds.). (1992). Energy metabolism, tissue determinants and cellular corollaries. Raven Press.

Manore, M., Meyer, N., \& Thompson, J. (Eds.). (2009). Human kinetics (ed.). Sport Nutrition for Health and Performance.

McArdle, W., Katch, F., \& Katch, V. (Eds.). (2010). Exercise physiology: nutrition, energy, and human performance. Lippincott Williams and Wilkins.

McDoniel, S., Nelson, H., \& Thomson, C. (2008). Employing rmr technology in a 90-day weight control program. Obesity Facts, 1(6), 298-304.

Nestle, M., \& Nesheim, M. (Eds.). (2012). Why calories count: from science to politics. University of California Press.

Orsi, C., Hale, D., \& Lynch, J. (2011). Pediatric obesity epidemiology. Current Opinion in Endocrinology Diabetes and Obesity, 18(1), 14-22.

Seagle, H., Strain, G., Makris, A., \& Reeves, R. (2009). Position of the american dietetic association: Weight management. Journal of the American Dietetic Association, 109, 330-346.

Spring, B., Pellegrini, C., Pfammatter, A., Duncan, J., Pictor, A., McFadden, H., Hedeker, D. (2017). Effects of an abbreviated obesity intervention supported by mobile technology: The engaged randomized clinical trial. Obesity, 25(7), 1191-1198.

Stump, C., Jackemeyer, D., Abidov, Y., Herbst, K., Tao, N., \& Forzani, E. (2017). Study of the effect of mobile indirect calorimeter on weight management. Global Journal of Obesity, Diabetes and Metabolic Syndrome, 4(2), 44-50.

Wahrlich, V., Anjos, L., Going, S., \& Lohman, T. (2006). Val- idation of the vo2000 calorimeter for measuring resting metabolic rate. Clinical Nutrition, 25(4), 687-692.

Weir, J. (1949). New methods for calculating metabolic rate with special reference to protein metabolism. Journal of Physiology, 109(1-2), 1-9.

Weir, J. (1990). Nutrition metabolism classic - new methods for calculating metabolic-rate with special reference to protein-metabolism. Journal of Nutrition, 6, 213-221.

Wolf, A., \& Colditz, G. (1998). Current estimates of the economic cost of obesity in the united states. Obesity Research, 6(2), 97-106.

Xian, X., Quach, A., Bridgeman, D., Tsow, F., Forzani, E., \& Tao, N. (2015). Personalized indirect calorimeter for energy expenditure (ee) measurement. Global Journal of Obesity, Diabetes and Metabolic Syndrome, 2(1), 004008 .

International Journal of Prognostics and Health Management, ISSN 2153-2648, 2021 